\title{
An Investigation of Three-Way Catalytic Converter for Various Inlet Cone Angles Using CFD
}

\author{
Sohel Khalil Shaikh ${ }^{1}$, Khizar Ahmed Pathan², Zakir Ilahi Chaudhary ${ }^{3}$, B. G. Marlpalle ${ }^{4}$, Sher Afghan \\ $\mathrm{Khan}^{5, *}$
}

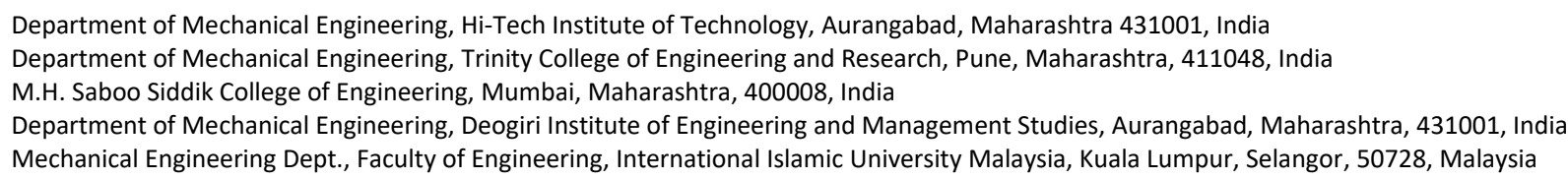

\section{ARTICLE INFO}

Article history:

Received 23 July 2020

Received in revised form 21 September 2020

Accepted 24 September 2020

Available online 30 September 2020

\section{Keywords:}

Automotive catalytic converter; diffuser angle; monolith diameter; flow index; pressure drop

\section{ABSTRACT}

Three-way catalytic converters are utilized to minimize exhaust emissions. The efficient working of catalytic converter depends upon the flow field developed inside the converter. Due to the prevailing stringent norms, such as Bharat stage- $\mathrm{VI}$, it is essential to create and design a high performing converter having uniform flow distribution within the converter to meet these norms. An easy way to gain an almost sufficiently homogeneous stream circulation is to compose the diffuser inclination minimally and correspondingly to manufacture the cone angle length long enough. The objective of the study is to examine an automobile catalytic convertor to present a detail and comprehensive report on the key parameters affecting the flow uniformity inside the converter and thus attempting to achieve minimum pressure drop across the converter to reduce the backpressure. They are modifying the existing geometry of the catalytic converter to have more uniform flow within the convertor. The analysis had been carried out with varying diffuser angles- 57.3, 52.3, and 45 degrees separately. Simulation program using computational fluid dynamics (CFD) software package STAR $\mathrm{CCM}+11.02$ was used. The monolith design with a 52.3을 cone angle evaluated with computations provides an actual parabolic curve, which gives a laminar flow within the catalytic converter, which in turn will increase the conversion efficiency of the converter by $1.060 \%$. The pressure drop within the monolith is also reduced by $3.7 \mathrm{~Pa}$. This accounts to be a reduction in backpressure up to $5 \%$, thus reduces brake specific fuel consumption of automobiles. The results are validated with the literature. The result shows the overall pressure drop augments with velocity. The temperature effect on light-off performance also studied.

Copyright @ 2020 PENERBIT AKADEMIA BARU - All rights reserved

\footnotetext{
* Corresponding author.

E-mail address: sakhan@iium.edu.my (Sher Afghan Khan)
} 


\section{Introduction}

The catalytic converter aims to convert harmful gasses like nitrogen oxide, carbon monoxide, hydrocarbons into less harmful gasses like $\mathrm{N}_{2}, \mathrm{O}_{2}$, etc. Noble metals like platinum, rhodium, and palladium are the noble metals used for the catalytic reaction inside the steel tube. Rhodium is employed as a stimulant, whereas palladium assists as an oxidizing agent. Rhodium is used to reduce NOx into $\mathrm{N}_{2}$. A cone angle of 6 to $10^{\circ}$ has been established suitable. The mass flow rate (mean channel momentum) must be utilized while evaluating the evenness holdings $\mathrm{H}$. Weltens et al., [1]. Chakravarthy et al., [2] employed an algebraic turbulence model for single convertor geometry in 2D and parameter such as temperature and reaction. The outcome was approved by applying experiments of Holmgren et al., [3]. Benjamin et al., [4] reported that accurate forecasting of maximum flow velocity is essential for the evaluation of catalyst deactivation and light-off time. The method is validated against the results of CFD. The results show flow profiles obtain by the CFD code and FRM technique to be a good agreement with experimental results. Subramanian et al., [5] carried out a study applied on three guidelines viz. catalytic converter length, cell densities, and metal loading. Cell density was changed from 200 cells per inch (CPI) to $1200 \mathrm{CPI}$, and lengths from 70 to $180 \mathrm{~mm}$ commercially available CFD software was used S. Subramanian [5]. Augmenting the convertor length improves light-off and maximum conversion; with increasing cell densities, the conversion efficiency of species rises up to a certain level. Hayes et al., [6] studied the effect of critical working parameters by changing the cell densities and wall thickness at constant wash coat loading.

Agrawal et al., [7] presented a report on the synergy between movement, backlash, and thermal effects in a 2 Dimension axis-symmetric convertor. The parabolic velocity profile in the transverse direction is expected for laminar flow. The response did not have a significant impact on flow distribution. The literature review suggested that the most influencing key parameter is the inlet cone angle and inlet cone length, not much work had been reported in the literature so as to emphasize the effect of cone angle in the flow distribution within the converter. This paper aims to change the inlet cone angle of the diffuser and plotting the pressure and velocity fields and flow uniformity index fields and also evaluating pressure and velocity intensity at critical locations inside the converter to get the most uniform flow inside the converter.

\section{Catalytic Converter Geometry}

The monolith consists of a number of channels, inlet and outlet cones with a three-dimensional representation. Labeled geometry is represented in Figure 1 (a) and (b).

The monolith substrate used was 100 CPSI with standard wall thickness. The dimensions and physical properties of the substrate are given in Table 1.

Table 1

Monolith brick specification

\begin{tabular}{ll}
\hline Properties & $100 \mathrm{CPSI}$ \\
\hline Wall thickness & $0.10 \mathrm{~mm}$ \\
Substrate Shape & Round \\
Open Frontal Area & 0.72 \\
Matrix Diameter & $2.5 \mathrm{~mm}$ \\
\hline
\end{tabular}




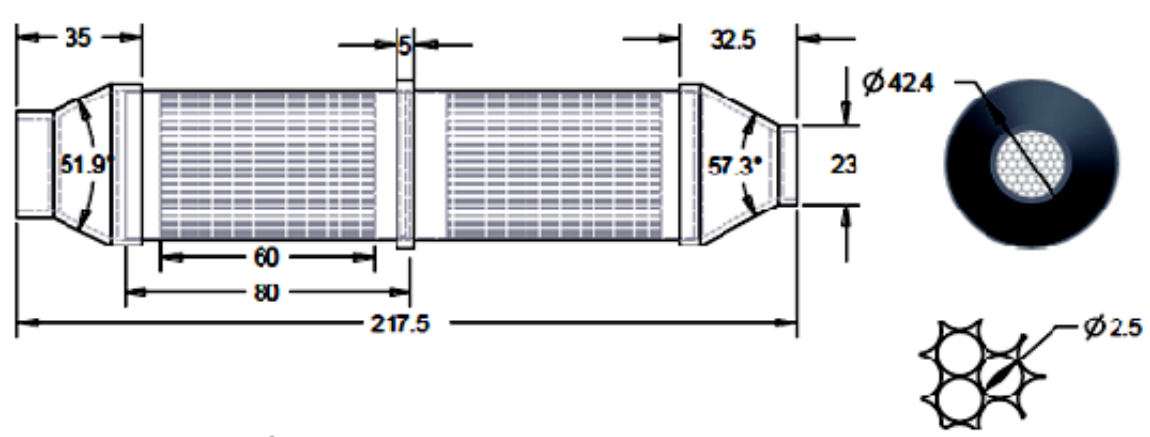

(a)

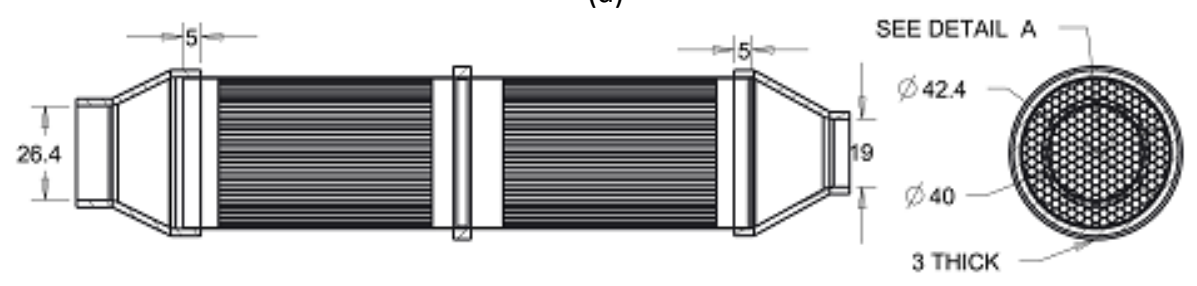

(b)

Fig.1. Schematic view of catalytic converter assembly All dimensions are in $\mathrm{mm}$

\subsection{Inlet Velocity Calculation}

The symbolic scope of momentum at the interior of block channels is 0 to $12 \mathrm{~m} / \mathrm{s}$. The mean velocity of 2 and $2.5 \mathrm{~m} / \mathrm{s}$ into an individual monolith route is used for the geometries. As per geometry, 240 cells in $42.4 \mathrm{~mm}$ diameter monolith are present. The Eqs. (1) to (7) are used to calculate inlet velocity.

$V_{\text {channel }}=2.5 \mathrm{~m} / \mathrm{s}$

$Q_{\text {channel }}=\frac{\Pi d^{2}}{4} \times V_{\text {Channel }} \times \operatorname{density}(\varsigma)$

$Q_{\text {channel }}=\frac{\Pi d^{2}}{4} \times V_{\text {Channel }} \times \operatorname{density}(\varsigma)$

$Q_{\text {channel }}=\frac{3.14 \times(0.0025)^{2}}{4} \times 2.5 \times 1.136=0.00001394 \mathrm{~kg} / \mathrm{s}$

$Q_{\text {total }}=0.00001394 \times 240=0.003345 \mathrm{~kg} / \mathrm{s}$

$Q_{\text {inlet }}=Q_{\text {total }}$

$0.003345=0.7854 \times 0.019^{2} \times v \times 1.136$

$V_{\text {inlet }}=10.38 \mathrm{~m} / \mathrm{s}$

Similarly, for $V_{\text {channel }}=2 \mathrm{~m} / \mathrm{s}$, the inlet velocity obtained is given by Eq. (8)

$V_{\text {inlet }}=8.31 \mathrm{~m} / \mathrm{s}$ 
Many authors [8-28] employed the Reynolds Averaged Navier-Stokes (RANS) mathematical statement having $k-€$ turbulence setup, where the $k$ is the turbulent kinetic energy, and $\omega$ is the specific dissipation rate. In this present work, polyhedral mesh elements have been used to get accurate results and to reduce computation time. Meshed model is shown in Figure 2 . The total mesh count was 7,537,067. The CFD package, STAR CCM + 11.02, is used for the analysis in present work.

Figure 3 shows three sections where pressure and velocity fields are evaluated. Three different geometry are analyzed: (a) base model geometry (cone angle $57.3^{\circ}$ ), (b) variant 01 geometry (cone angle $52.3^{\circ}$ ), and (c) variant 02 geometry (cone angle $45^{\circ}$ ). The central variation with the other efforts $[2,6]$ is that they defined the block as a permeable element. Consequently, a multi-channel geometry was considered, as shown in Figure 1 . Figure 3 shows three vertical lines (labeled $v_{1}, v_{2}$, and $v_{3}$ ) in a line is the cross-section area where the momentum study is interpreted comprehensively.

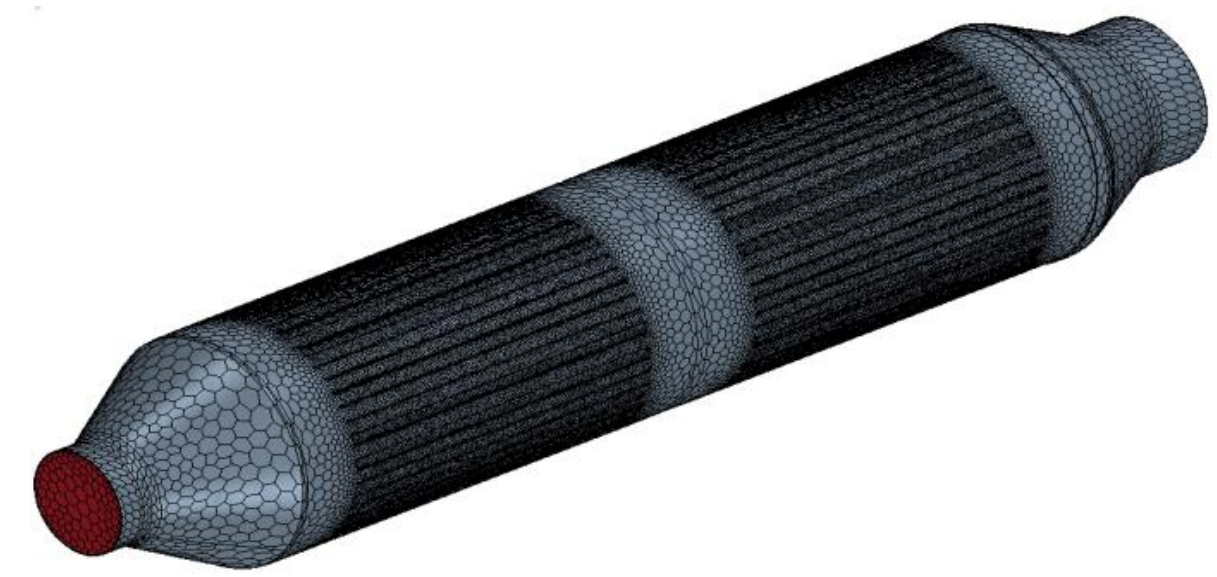

Fig.2. The meshed fluid domain of catalytic converter

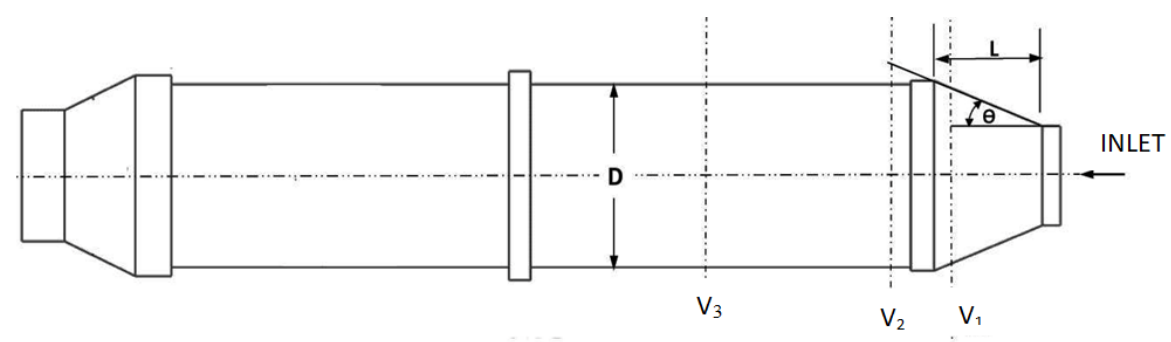

Fig. 3. Symbolic of even two-dimensional geometry of the catalytic converter

\subsection{Inlet Boundary Requisite}

At the inlet, to the catalytic converter, a velocity of $10.38 \mathrm{~m} / \mathrm{s}$ and $8.31 \mathrm{~m} / \mathrm{s}$ was considered. The inlet temperature is $27^{\circ} \mathrm{C}$. For $10.38 \mathrm{~m} / \mathrm{s}$ situation, the Reynolds number (established upon hydraulic diameter) inside every brick carrier is $R e c h=378$. The momentum at the interior of the brick carriers is laminar. The following parameters, like turbulence lens scale, solver setting, etc., chosen were default values as reported by $\mathrm{H}$. Weltens et al., [2]. The fluid is selected (nitrogen), and the properties and temperature are shown in Table 2. 


\section{Table 2}

Functional conditions and variables for the catalytic convertor simulations

\section{Brick carrier outline}

Brick dimension

Carrier bore

Wall thickness

Average velocity

Channel Reynolds number

Inlet conditions

Inlet velocity

Temperature

Pressure

Density

Viscosity
$60 \mathrm{~mm}$

$2.5 \mathrm{~mm}$

$0.10 \mathrm{~mm}$

$2.5 \mathrm{~m} / \mathrm{s}$

378

$\mathrm{V} 1=10.38 \mathrm{~m} / \mathrm{s}$ and

$\mathrm{V} 2=8.31 \mathrm{~m} / \mathrm{s}$

$300 \mathrm{~K}$

$1 \mathrm{~atm}$

$1.136 \mathrm{Kg} / \mathrm{m}^{3}$

$1.6638 * 10-05 \mathrm{Kg} / \mathrm{m}-\mathrm{s}$

\section{Results and Discussion}

\subsection{Validation}

Before the parametric studies, the prediction of the base models was compared to some literature results. The result reported by Pushpavanam et al., [7] have used 85 channels ceramic monolith with wall thickness $400 \mu \mathrm{m}$, the inlet diameter of $40 \mathrm{~mm}$, the diffuser length was $53 \mathrm{~mm}$, and the inlet flow velocity was $10.63 \mathrm{~m} / \mathrm{s}$.

It can be seen from Figures 4 and 5; the pattern of the literature result is similar to that of the simulated ones. The net deviation from the maximum centerline velocity is approximately $5 \%$. This indicated that the established model is feasible and can be used to study the flow characteristics for the convertor with various configurations. There are many possible explanations for the errors between literature results and simulation results. They may be associated with turbulence model numerically inaccuracy or geometrical design.

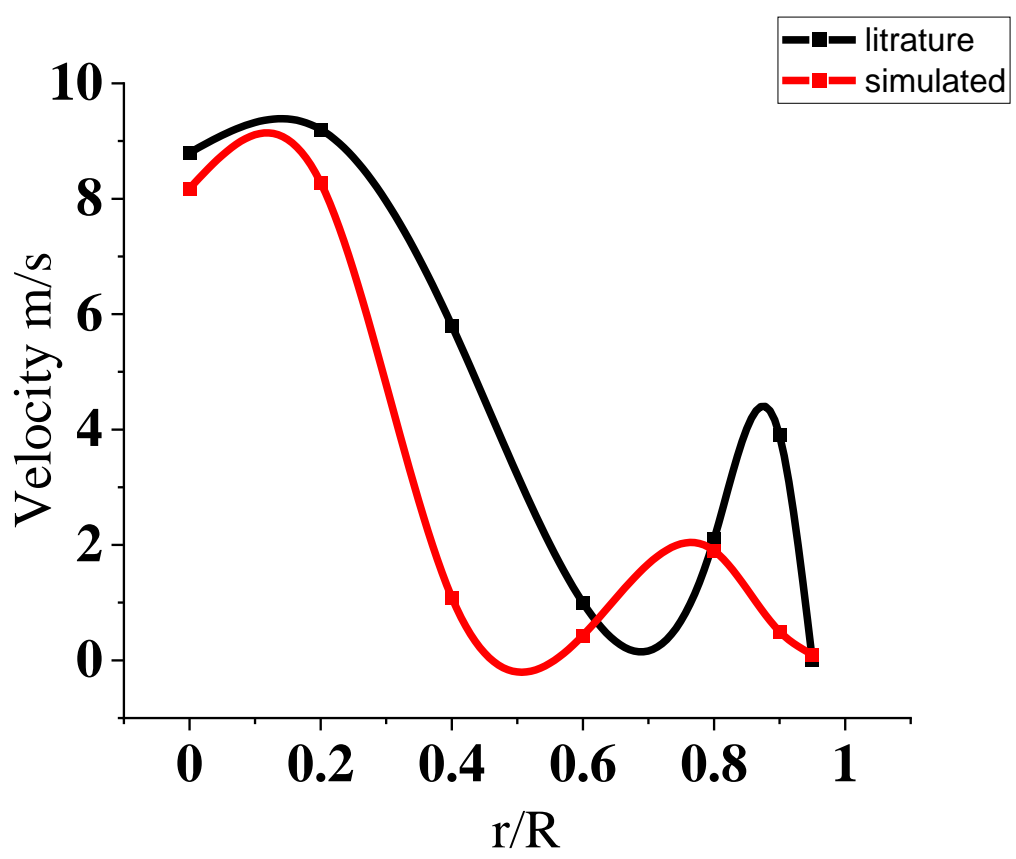

Fig. 4. Momentum intensity Vs. non-dimensional diagonal coordinate at location $\mathrm{v}_{1}$ 


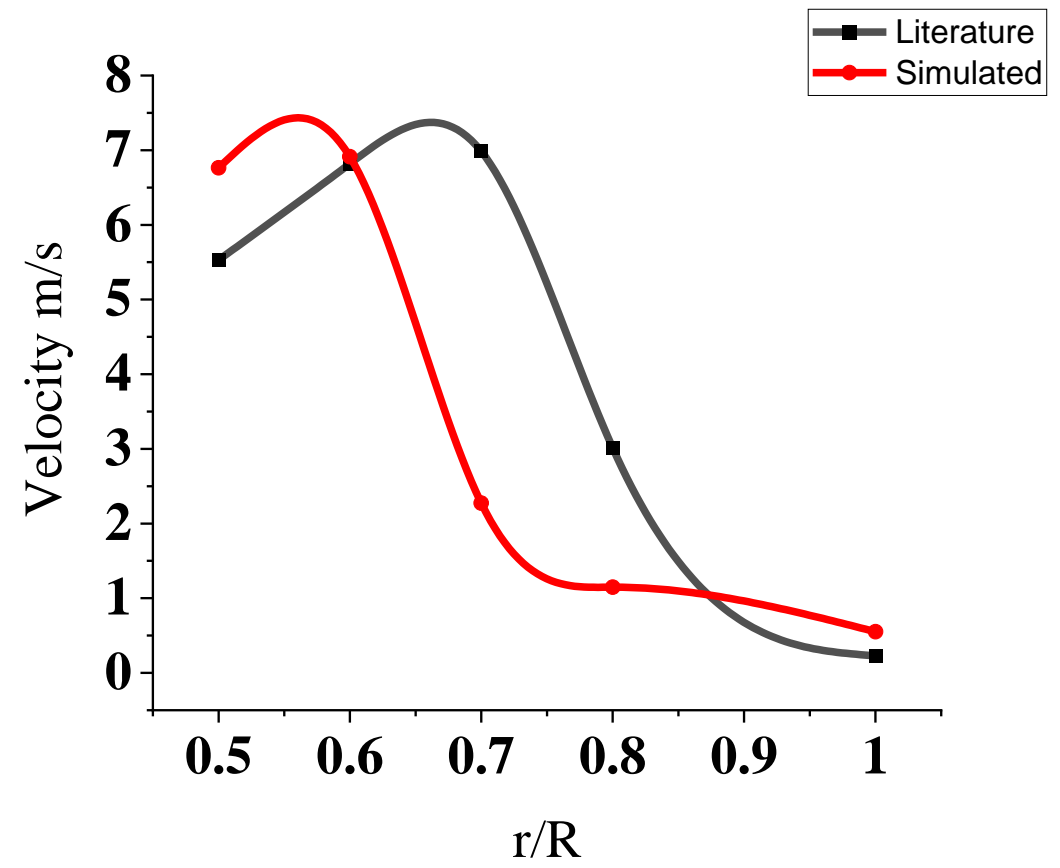

Fig. 5. Momentum intensity Vs. non-dimensional diagonal coordinate at location $v_{2}$

\section{CFD Results}

Three simulation run analysis results are presented for pressure drop characteristics and flow uniformity index, as shown in the Table 3.

\section{Table 3}

Geometry design for simulation confirmation

\begin{tabular}{lllll}
\hline \multicolumn{2}{l}{ Cone angle (degrees) brick dimensionbrick borelnlet pipe diameterlnlet pipe length } \\
\hline 57.3 & 60 & 40 & 19 & 21.5 \\
52.3 & 60 & 40 & 19 & 23.92 \\
45 & 70 & 37.03 & 19 & 28.35 \\
\hline
\end{tabular}

The grid independence test has been conducted for different mesh element sizes. Table 4 shows the results obtained by the CFD analysis at various mesh element sizes.

\section{Table 4}

The mesh dependency test for external flow

\begin{tabular}{lll}
\hline Mesh Max Size & Mesh Elements & Dimensionless Pressure \\
\hline 5 & 1351 & 0.997422734 \\
4 & 1551 & 0.998361998 \\
3 & 1970 & 0.998282478 \\
2 & 12221 & 0.998697340 \\
1 & 18795 & 0.999215397 \\
0.5 & 134946 & 0.999209453 \\
0.4 & 154641 & 0.999222551 \\
\hline
\end{tabular}




\subsection{Flow Distribution Inside the Converter}

\subsubsection{Flow velocity computations}

Figure 6 shows that the base model transverse velocity profile is not following the parabolic curve. Near the circular boundary of the converter, there is higher resistance to flow offered, which introduces a considerable amount of non-uniformity within the converter and will result in lesser conversion efficiencies rates. The flow no more remains laminar near the boundary of the converter. Reducing the cone angle to $45^{\circ}$ makes the transverse velocity profile more parabolic curve (expected for laminar flow).

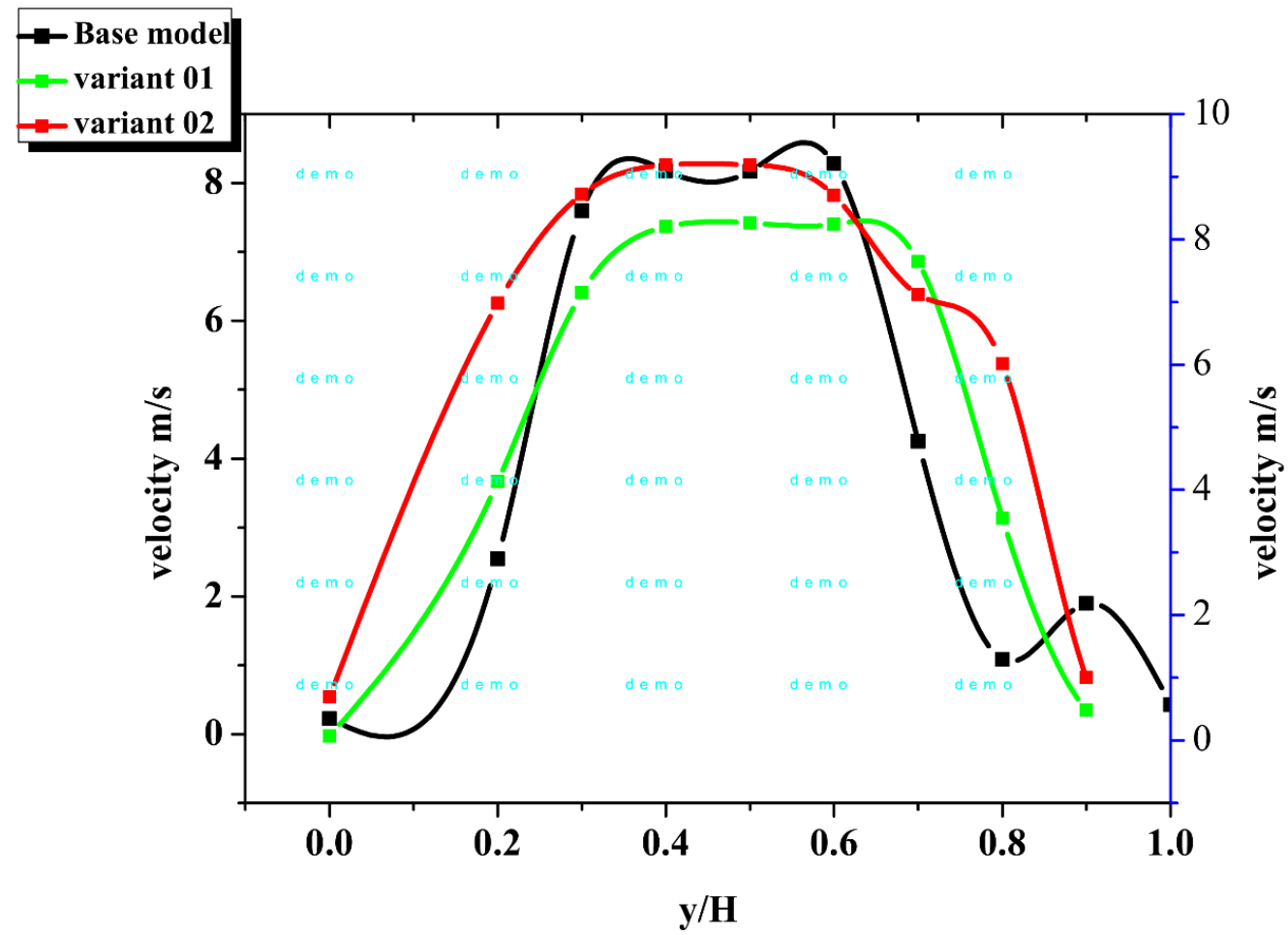

Fig. 6. The intensity of magnitude $\mathrm{Vs}$ the non-dimensional distance along with the diagonal path correlative to $10.38 \mathrm{~m} / \mathrm{s}$ inlet velocity at $\mathrm{v}_{1}$ location

This study aims to obtain a correct parabolic curve in nature so that the flow in the converter will be uniform flow, which will result in the highest conversion efficiency of harmful gasses into less harmful gasses, hence the more efficient design of converter is considered. Figure 7 shows the variant 02 model has a parabolic curve in nature, the maximum velocity at the center of the convertor $7 \mathrm{~m} / \mathrm{s}$.

The flow is also near to laminar flow for the variant 01 models shown by the parabolic curve in the above Figure 8 . From Figures 6,7 , and 8 , the most promising model is variant 01 , which is showing nearly a parabolic curve at all three locations $V_{i z}: v_{1}, v_{2}, v_{3}$. The flow behavior at these three locations is qualitatively similar to that obtained for the inlet velocity corresponding to $8.31 \mathrm{~m} / \mathrm{s}$. 


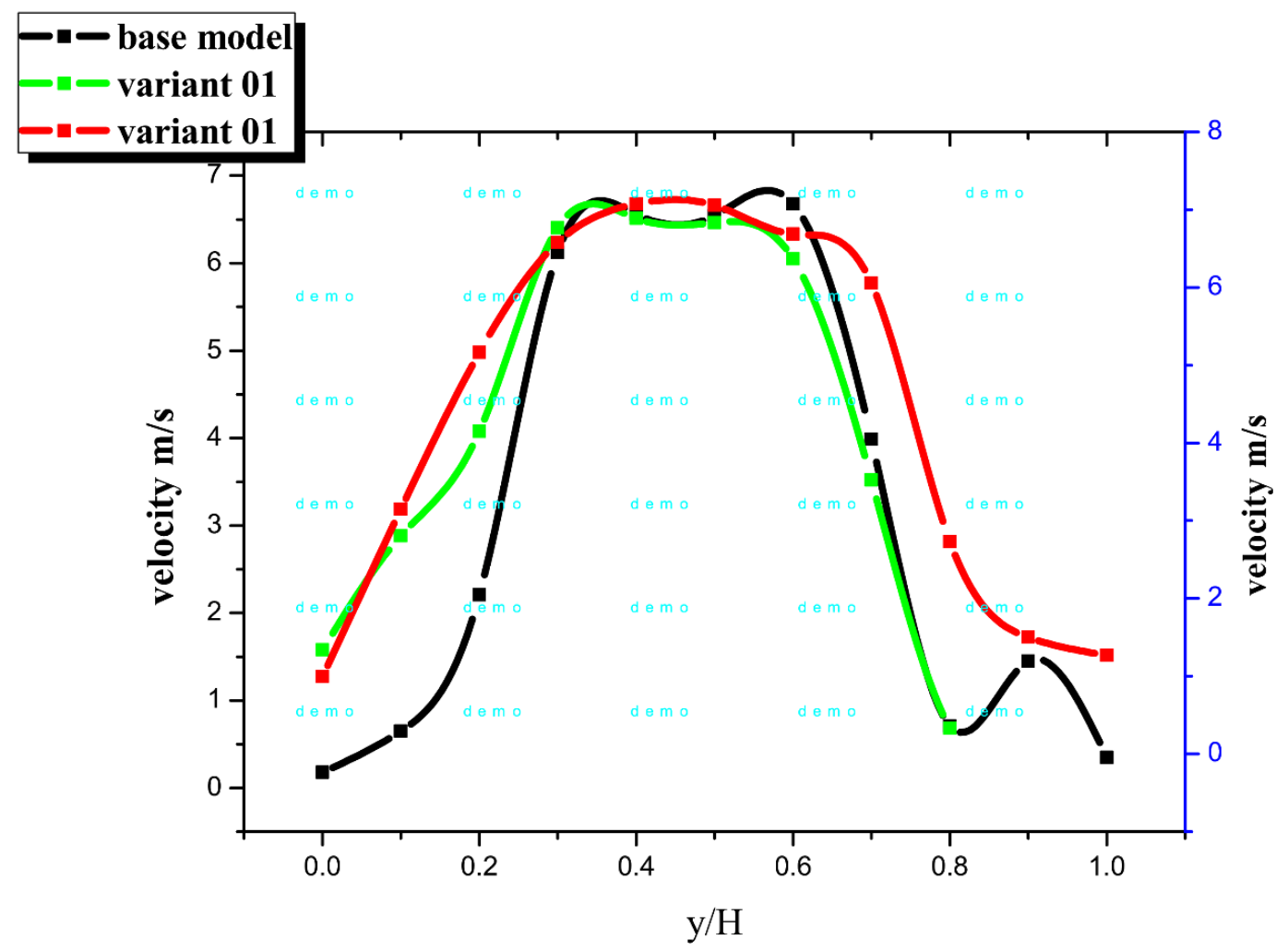

Fig. 7. The intensity of magnitude Vs. the Non-dimensional distance along with the diagonal path correlative to $10.38 \mathrm{~m} / \mathrm{s}$ inlet velocity at $\mathrm{v}_{2}$ location

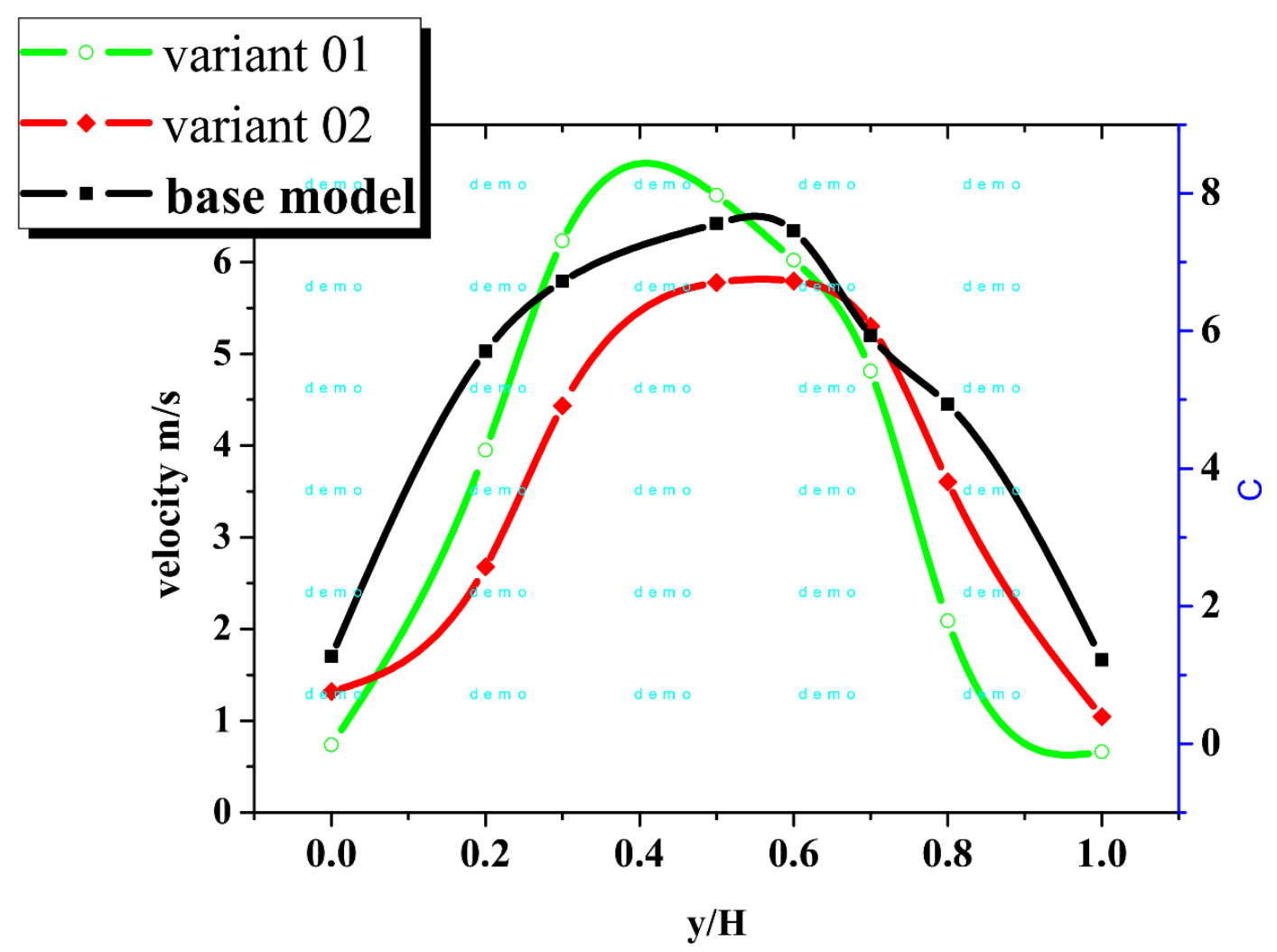

Fig. 8. The intensity of magnitude Vs. the non-dimensional distance along with the diagonal path correlative to $10.38 \mathrm{~m} / \mathrm{s}$ inlet velocity at $\mathrm{v}_{3}$ location 


\subsubsection{Pressure computations}

The Pressure analysis is also evaluated at these three locations, and the graph is plotted for calculated inlet velocities. The pressure graph from Figure 9 indicates a rise in pressure in the transverse direction in variant 02 is high as compare to option 01 and the base model. The pressure here is $62 \mathrm{~Pa}$ for variant 02 , a value higher than $17 \mathrm{~Pa}$ as compare to other designs. Also, the peak pressure rise is lower in the variant 01 models as compared to the base model. Small growth in pressure will not introduce vorticity within the flow, and flow will remain uniform within the converter.

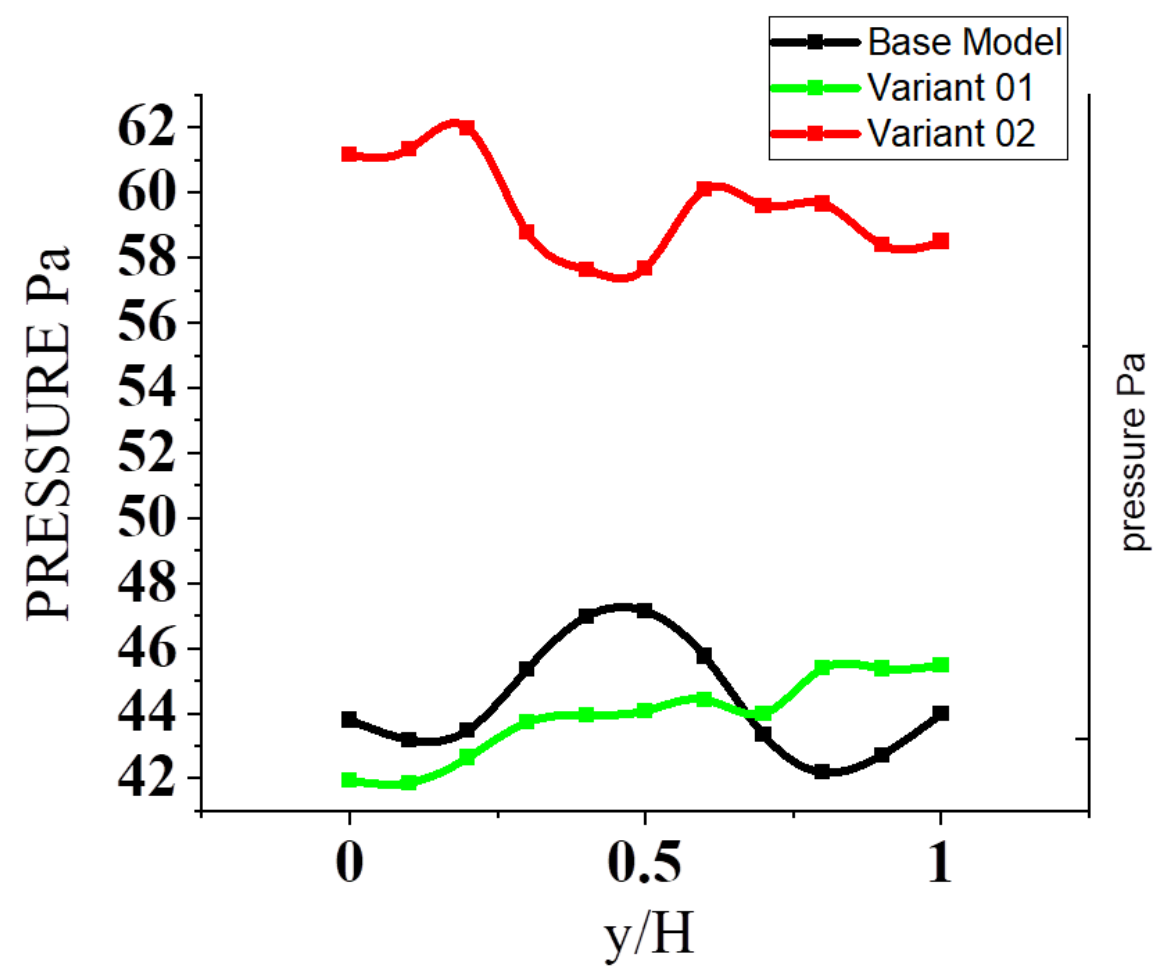

Fig. 9. Pressure Vs. the non-dimensional distance along with the diagonal path correlative to $10.38 \mathrm{~m} / \mathrm{s}$ inlet velocity at $\mathrm{v}_{1}$ location

There is a rise in pressure for variant 02 in a transverse direction, indicating a value of $80 \mathrm{~Pa}$ in Figure 10 as it was $62 \mathrm{~Pa}$ at $\mathrm{v}_{1}$ location for the same geometry. There is also a rise in pressure values for other designs as compared to pressure values at the same places.

Based on the obtained results from Figures 9 and 10, it is concluded that decreasing the diffuser angle gives rise to pressure in a transverse direction. It is observed from Figure 11 that just at the upstream location of the diffuser, the flow is highly non-uniform because at such a high-pressure rise introduces turbulence in the flow of gas. It is a highly undesirable flow and must be avoided by changing specific design parameters. 


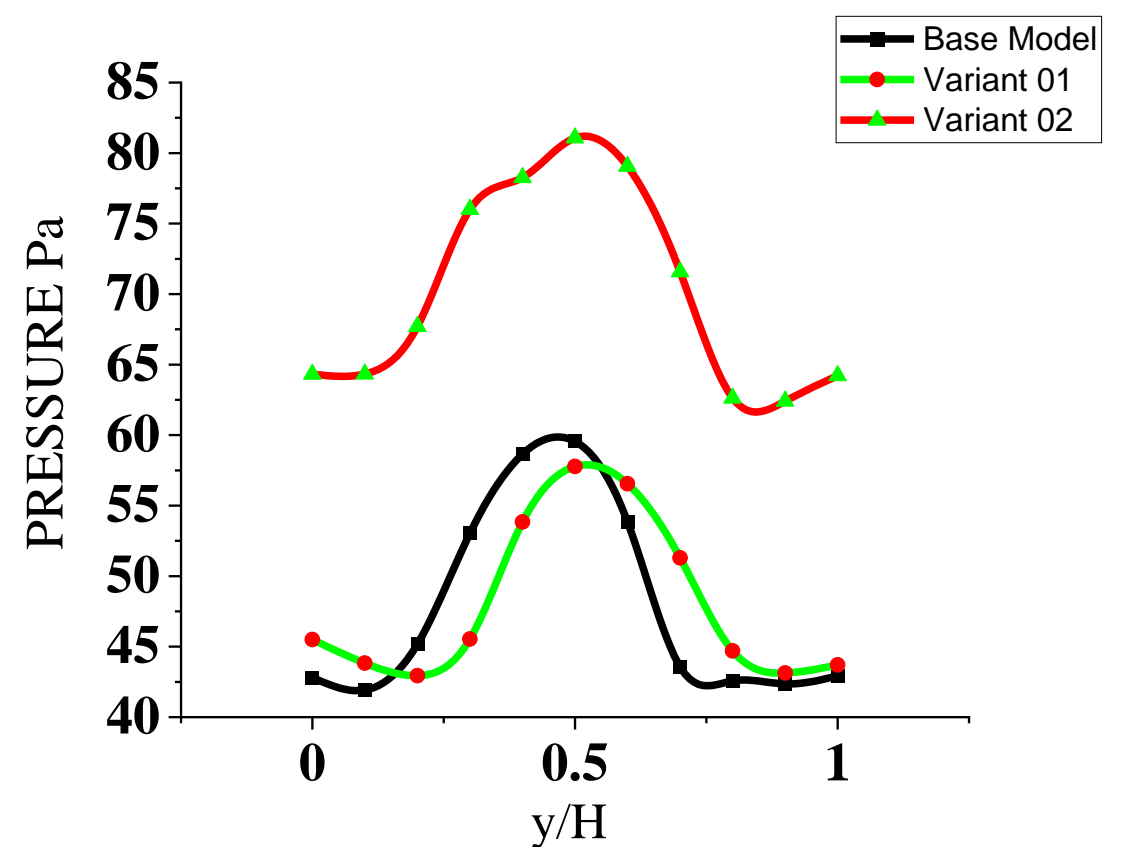

Fig. 10. Pressure Vs. the non-dimensional distance along with the diagonal path correlative to $10.38 \mathrm{~m} / \mathrm{s}$ inlet velocity at $\mathrm{v}_{2}$ location

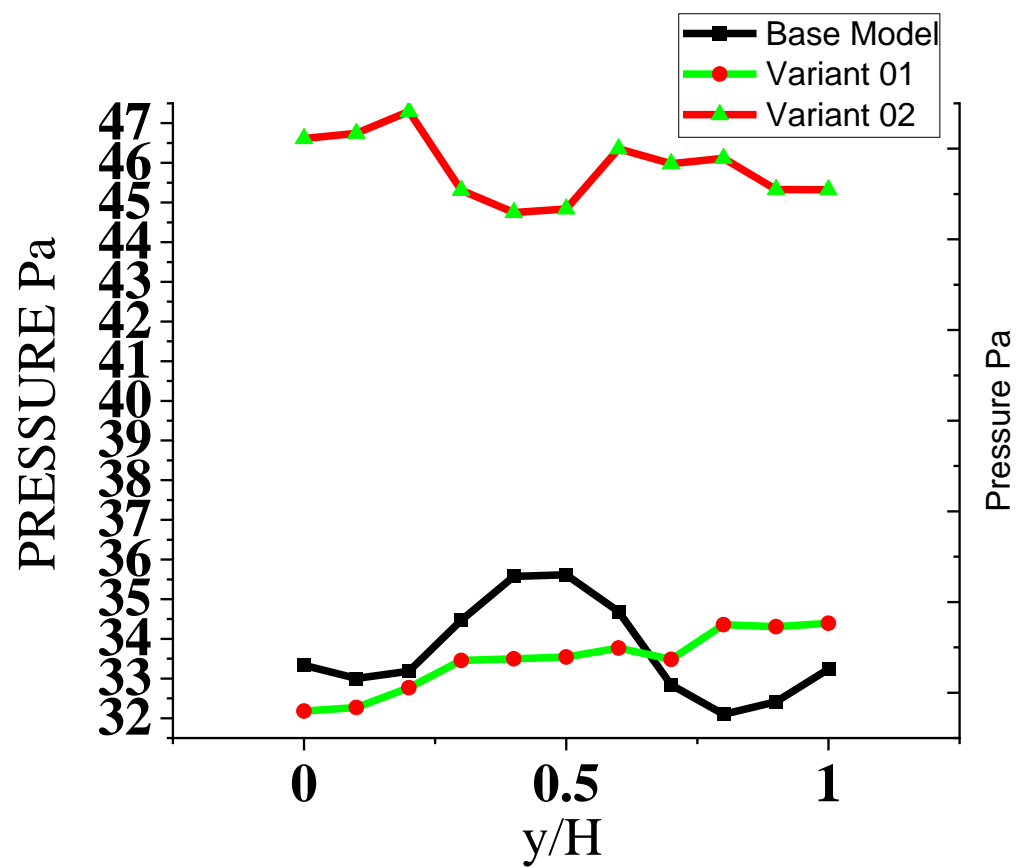

Fig. 11. pressure Vs. the non-dimensional distance along with the diagonal path correlative to $8.31 \mathrm{~m} / \mathrm{s}$ inlet velocity at $\mathrm{v}_{1}$ location

From Figure 12, it can be conferred that the value of maximum velocities for all three variants is less concerning to corresponding values of velocities at $10.38 \mathrm{~m} / \mathrm{s}$ inlet.

From Figure 12, it can be seen that the velocity profile for variant 01 is parabolic in nature, which is termed as the maximum centerline velocity for the variant 01 model is $6 \mathrm{~m} / \mathrm{s}$. The trend for the velocity profile is exact as compared to the inlet velocity of $10.38 \mathrm{~m} / \mathrm{s}$ at location $v_{1}$. The maximum pressure rise in the transverse direction is $33 \mathrm{~Pa}$ for variant 01 model, which is the comparatively lesser value at the same location corresponding to inlet velocity $10.38 \mathrm{~m} / \mathrm{s}$. This indicates at higher velocities and flows, mal-distribution will be higher. 


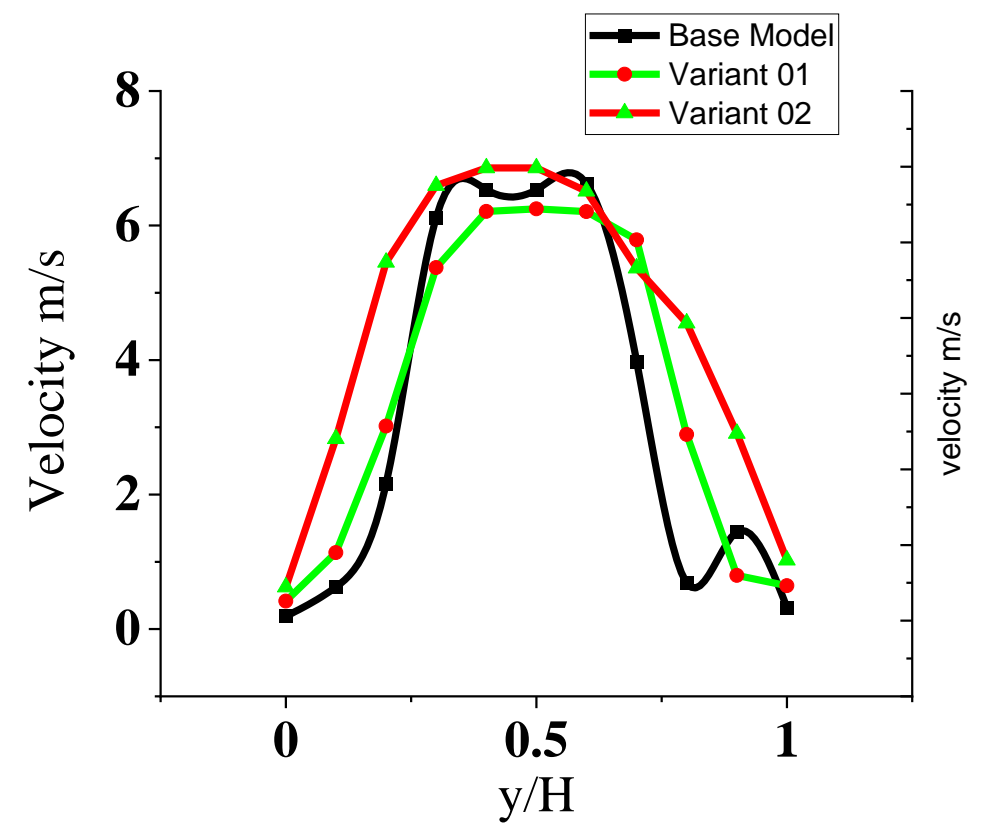

Fig. 12. Velocity Vs. the non-dimensional distance along with the diagonal path correlative to $8.31 \mathrm{~m} / \mathrm{s}$ inlet velocity at $\mathrm{v}_{1}$ location

\subsubsection{Pressure drop characteristics}

The pressure drop characteristics, i.e., pressure difference at inlet and outlet of the converter, are also studied by estimating the numerical values of pressure across the catalytic converter. The Figure 13 indicated the minimum value of pressure drop is for variant 02 is $62.7 \mathrm{~Pa}$, corresponding to $52.3^{\circ}$ cone angle for inlet velocity $10.38 \mathrm{~m} / \mathrm{s}$, decreasing the additional amount of diffuser angle increases the pressure drop. Similarly, for $8.31 \mathrm{~m} / \mathrm{s}$, the value of pressure drop is less as compared to inlet velocity $10.38 \mathrm{~m} / \mathrm{s}$, for cone angle $52.3^{\circ}$ is $45.4 \mathrm{~Pa}$.

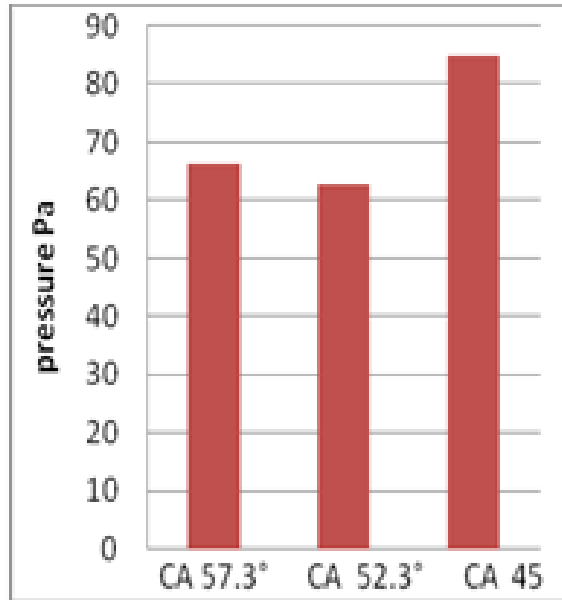

(a) $10.38 \mathrm{~m} / \mathrm{s}$

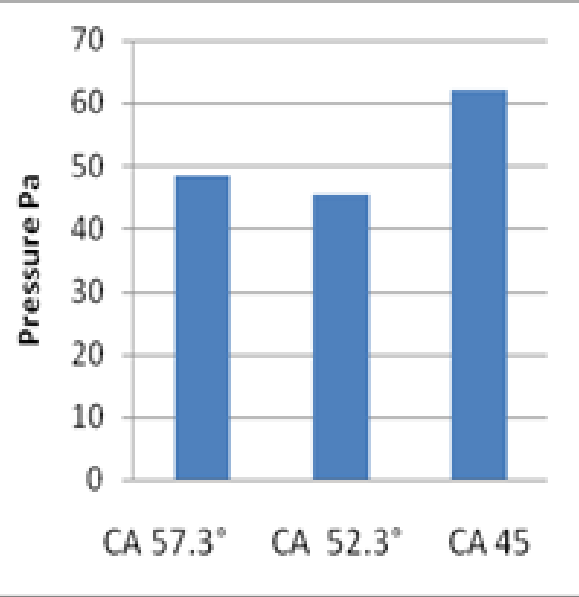

(b) $8.31 \mathrm{~m} / \mathrm{s}$

Fig. 13. Influence of cone angle (CA) on pressure drop corresponding to inlet velocity $10.38 \mathrm{~m} / \mathrm{s}$ and $8.31 \mathrm{~m} / \mathrm{s}$ 


\section{Flow Uniformity Index}

A dimensionless parameter-flow uniformity index $(\gamma)$ indicates the range of flow mal-distribution inside the monolith channels. Ideally, $\gamma$ should be one for normal- distribution inside the monolith. The flow index value is 1.9 at the center of the channels. Figure 14 shows a uniform flow inside the catalytic convertor for variant 02 model, followed by the variant 01 models as compared to base geometry design.

The flow index for the variant 02 models is 1.62, which is a lower value as compared to the inlet velocity of $10.38 \mathrm{~m} / \mathrm{s}$ at the same location. This shows that flow mal-distribution is higher at higher velocities. In summary

i. The variant 01 model offers a lower pressure drop value as compared to other geometrical designs and also has uniform flow as compared to the base model design.

ii. A decrease in the cone angle makes the flow inside the convertor a uniform flow but increases the pressure drop characteristics across the convertor.

From Figures 14 and 15, the flow is more uniform at the center of the monolith as compared to near the inner walls of the catalytic converter. It may be as there are vortices created in the flow near the walls due to this, there is flow mal-distribution near the circumference of the catcon, and at the center, and there is the greater amount of mass flow rates.

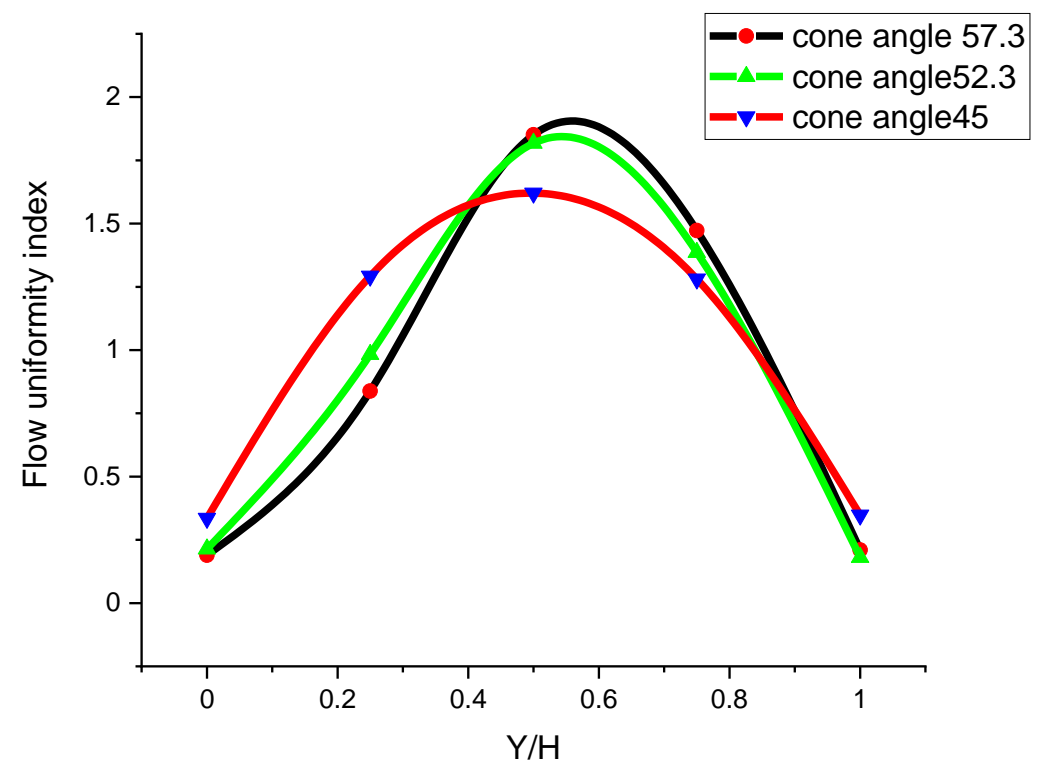

Fig. 14. Flow index Vs. the non-dimensional distance along with the diagonal path correlative to $10.38 \mathrm{~m} / \mathrm{s}$ inlet velocity at $\mathrm{v}_{3}$ location 


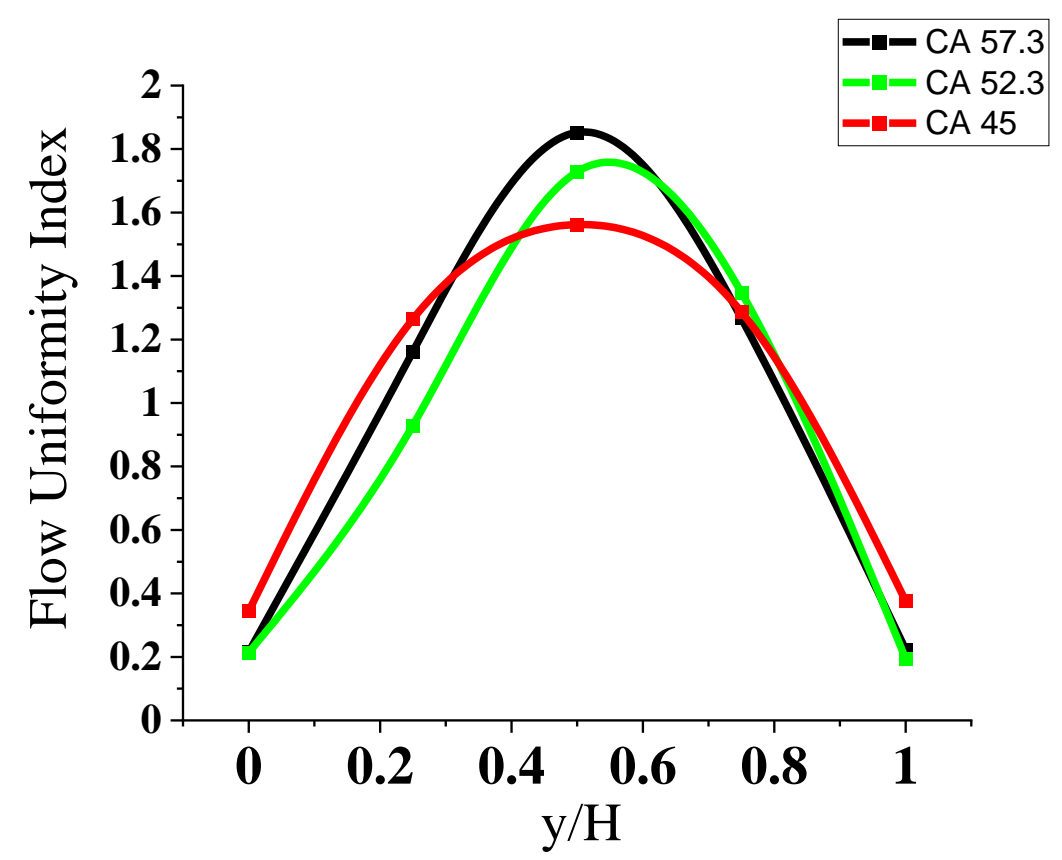

Fig. 15. Flow index Vs. Non-dimensional distance in the transverse direction corresponding to $8.31 \mathrm{~m} / \mathrm{s}$ inlet velocity at $\mathrm{v}_{3}$ location

\section{Conclusions}

The stream circulation in a base design brick is uneven because of the geometry of the estuary features and catalytic monolith. Due to the presence of powerful recirculation zones, the flow is termed as non-uniform. The velocity profile curves for inlet velocity $10.38 \mathrm{~m} / \mathrm{s}$ for base design geometry at the different transverse location was compared with the existing literature results. The trend depicted was similar in both cases. The deviation from maximum velocity is within an acceptable range of $3 \%$. This shows that the model is established and can be modified to obtain different analysis results.

As seen from the results, to minimize the flow mal-distribution within the convertor, the critical parameter is optimizing diffuser geometry. Flow separation occurs within the distribution leading to a non-uniform flow. There is an increase in pressure filed values in the transverse direction at $v_{2}$ location; this is because the diffuser increases the pressure of the fluid at the expense of its kinetic energy.

The overall pressure drop increases with an increase in inlet velocities. For $10.38 \mathrm{~m} / \mathrm{s}$, the total pressure drop is $84.9 \mathrm{pa}$, corresponding to the $45^{\circ}$ cone angle. There is a reduction in flow separation as the cone angle reduces to $45^{\circ}$, minimizing the flow maldistribution within the converter. One of the reasons for the increase in overall pressure drop at reduced diffuser angle is, the flow area of the diffuser will become smaller and smaller as the inclined angle reduces, thus decreasing the flow uniformity index and increasing the pressure loss.

The variant 01 models with diffuser angle $52.3^{\circ}$ shows favorable conditions with a limited overall pressure drop value of $62.7 \mathrm{pa}$ as compared to the base design value of 66.4pa corresponding to inlet velocity $10.38 \mathrm{~m} / \mathrm{s}$, the design can achieve an improvement in pressure drop value of $3.7 \mathrm{pa}$. The result is similar for inlet velocity $8.31 \mathrm{~m} / \mathrm{s}$, here a pressure drop improvement value is $2.7 \mathrm{pa}$. The engine exhaust backpressure is directly proportional to the pressure drop across the converter. The minimum amount of the pressure drop will exert lower back pressure on the engine. Reduction in backpressure will lead to reduced specific fuel consumption. The flow uniformity index value is enhanced as compared to the base design, indicating a more uniform flow than its original geometry. 


\section{References}

[1] Weltens, Herman, Harald Bressler, Frank Terres, Hubert Neumaier, and Detlev Rammoser. Optimisation of catalytic converter gas flow distribution by CFD prediction. No. 930780. SAE Technical Paper, 1993.

https://doi.org/10.4271/930780

[2] Chakravarthy, V. K., J. C. Conklin, C. S. Daw, and E. F. D’Azevedo. "Multi-dimensional simulations of cold-start transients in a catalytic converter under steady inflow conditions." Applied Catalysis A: General 241, no. 1-2 (2003): 289-306. https://doi.org/10.1016/S0926-860X(02)00490-8

[3] Holmgen, A., T. Grontedt, and B. Andersson. "Improved flow distribution in automotive monolith converters." React. Kinet. Catal. Lett 60, no. 2 (1997): 363-371.

https://doi.org/10.1007/BF02475700

[4] Benjamin, Stephen F., Z. Liu, and Carol A. Roberts. "Automotive catalyst design for uniform conversion efficiency." Applied Mathematical Modelling 28, no. 6 (2004): 559-572.

https://doi.org/10.1016/i.apm.2003.10.008

[5] Kumar, M. Senthil, and Sendilvelan Subramanian. CFD Analysis of a Catalytic Converter Using Supported Copper Catalyst to Reduce Particulate Matter and Achieve Limited Back Pressure in Diesel Engine Exhaust. No. 2011-011245. SAE Technical Paper, 2011.

[6] Hayes, R. E., Anton Fadic, Joeseph Mmbaga, and A. Najafi. "CFD modelling of the automotive catalytic converter." Catalysis today 188, no. 1 (2012): 94-105.

https://doi.org/10.1016/j.cattod.2012.03.015

[7] Agrawal, Gaurav, Niket S. Kaisare, S. Pushpavanam, and Karthik Ramanathan. "Modeling the effect of flow maldistribution on the performance of a catalytic converter." Chemical engineering science 71 (2012): 310-320. https://doi.org/10.1016/j.ces.2011.12.041

[8] Pathan, Khizar Ahmed, Prakash S. Dabeer, and Sher Afghan Khan. "Investigation of base pressure variations in internal and external suddenly expanded flows using CFD analysis." CFD Letters 11, no. 4 (2019): 32-40.

[9] Pathan, Khizar Ahmed, Prakash S. Dabeer, and Sher Afghan Khan. "Effect of nozzle pressure ratio and control jets location to control base pressure in suddenly expanded flows." Journal of Applied Fluid Mechanics 12, no. 4 (2019): 1127-1135. https://doi.org/10.29252/jafm.12.04.29495

[10] Khizar Ahmed Pathan, Prakash S. Dabeer, and S. A. Khan. "An Investigation of Effect of Control Jets Location and Blowing Pressure Ratio to Control Base Pressure in Suddenly Expanded Flows." Journal of Thermal Engineering 6, no. 11, (2020): 15-23. https://doi.org/10.18186/thermal.726106

[11] Khizar A. Pathan, P. S. Dabeer, and Sher Afghan Khan. "Influence of Expansion Level on Base Pressure and Reattachment Length." CFD Letters 11, no. 5 (2019): 22-36.

[12] Khan, Sher Afghan, M. A. Fatepurwala, and K. N. Pathan. "CFD analysis of human powered submarine to minimize drag." Ratio (L/D) 4 (2018): 5.

[13] Sher Afghan Khan, Abdul Aabid, Fharukh Ahmed Mehaboobali Ghasi, Abdulrahman Abdullah Al-Robaian, and Ali Sulaiman Alsagri. "Analysis of area ratio in a CD nozzle with suddenly expanded duct using CFD method." CFD Letters 11, no. 5 (2019): 61-71.

[14] Pathan, Khizar A., Prakash S. Dabeer, and Sher A. Khan. "Enlarge duct length optimization for suddenly expanded flows." Advances in Aircraft and Spacecraft Science 7, no. 3 (2020): 203-214.

[15] Khizar Ahmed Pathan, Syed Ashfaq, Prakash S Dabeer, and Sher Afgan Khan. "Analysis of Parameters Affecting Thrust and Base Pressure in Suddenly Expanded Flow from Nozzle." Journal of Advanced Research in Fluid Mechanics and Thermal Sciences 64, no. 1 (2019): 1-18.

[16] Delvi, Hamza Afser, Mohammed Faheem, Abdul Aabid, M. C. Math, and Sher Afghan Khan. "Investigation of Characteristics of Spark Ignition Engine Fuelled with Ethanol-Gasoline Blends Using Iso-octane Additive." Journal of Advanced Research in Fluid Mechanics and Thermal Sciences 66, no. 1 (2020): 151-163.

[17] Pathan, Khizar Ahmed, Prakash S. Dabeer, and Sher Afghan Khan. "An investigation to control base pressure in suddenly expanded flows." International Review of Aerospace Engineering (I. RE. AS. E) 11, no. 4 (2018): 162-169. https://doi.org/10.15866/irease.v11i4.14675

[18] Pathan, Khizar Ahmed, Prakash S. Dabeer, and Sher Afghan Khan. "Optimization of area ratio and thrust in suddenly expanded flow at supersonic Mach numbers." Case studies in thermal engineering 12 (2018): 696-700. https://doi.org/10.1016/i.csite.2018.09.006 
[19] Pathan, Khizar Ahmed, Sher Afghan Khan, and P. S. Dabeer. "CFD analysis of effect of flow and geometry parameters on thrust force created by flow from nozzle." In 2017 2nd International Conference for Convergence in Technology (I2CT), pp. 1121-1125. IEEE, 2017. https://doi.org/10.1109/I2CT.2017.8226302

[20] Pathan, Khizar Ahmed, Sher Afghan Khan, and P. S. Dabeer. "CFD analysis of effect of area ratio on suddenly expanded flows." In 2017 2nd International Conference for Convergence in Technology (I2CT), pp. 1192-1198. IEEE, 2017. https://doi.org/10.1109/12CT.2017.8226315

[21] Pathan, Khizar Ahmed, Sher Afghan Khan, and P. S. Dabeer. "CFD analysis of effect of Mach number, area ratio and nozzle pressure ratio on velocity for suddenly expanded flows." In 2017 2nd International Conference for Convergence in Technology (I2CT), pp. 1104-1110. IEEE, 2017. https://doi.org/10.1109/12CT.2017.8226299

[22] Khan, Sher Afghan, and Ethirajan Rathakrishnan. "Control of suddenly expanded flow from correctly expanded nozzles." International Journal of Turbo and Jet Engines 21, no. 4 (2004): 255-278. https://doi.org/10.1515/TJJ.2004.21.4.255

[23] Sajali, Muhammad Fahmi Mohd, Abdul Aabid, Sher Afghan Khan, Fharukh Ahmed Ghasi Mehaboobali, and Erwin Sulaeman. "Numerical investigation of flow field of a non-circular cylinder." CFD Letters 11, no. 5 (2019): 37-49.

[24] Khan, Sher Afghan, Abdul Aabid, and C. Ahamed Saleel. "Influence of micro jets on the flow development in the enlarged duct at supersonic Mach number." International Journal of Mechanical and Mechatronics Engineering 19 no. 1 (2019): 70-82.

[25] Asadullah, Mohammed, Sher Afghan Khan, Waqar Asrar, and E. Sulaeman. "Low-cost base drag reduction technique." Int. J. Mech. Eng. Robot. Res 7, no. 4 (2018): 428-432. https://doi.org/10.18178/ijmerr.7.4.428-432

[26] FAG, M., and S. A. Khan. "Active Control of Base Pressure using Micro Jets for Area Ratio of 7.56." Int. J. Innov. Technol. Explor. Eng 8: 491-495.

[27] Khan, Ambareen, Nurul Musfirah Mazlan, Mohd Azmi Ismail, and Mohammad Nishat Akhtar. "Experimental and Numerical Simulations at Sonic and Supersonic Mach Numbers for Area Ratio 7.84." CFD Letters 11, no. 5 (2019): 50-60.

[28] Khan, Sher Afghan, Abdul Aabid, Imran Mokashi, and Zaheer Ahmed. "Effect of Micro Jet Control on the Flow Filed of the Duct at Mach 1. 5." International Journal of Recent Technology and Engineering (IJRTE) 8: 1758-1762. https://doi.org/10.35940/ijrte.B1148.0882S819 